\title{
Theory and Developments in an Unobtrusive Cardiovascular System Representation: Ballistocardiography
}

\author{
Eduardo Pinheiro*, Octavian Postolache and Pedro Girão
}

Instituto de Telecomunicações, Instituto Superior Técnico, Torre Norte piso 10, Av. Rovisco Pais 1, 1049-001, Lisboa, Portugal

\begin{abstract}
Due to recent technological improvements, namely in the field of piezoelectric sensors, ballistocardiography an almost forgotten physiological measurement - is now being object of a renewed scientific interest.

Transcending the initial purposes of its development, ballistocardiography has revealed itself to be a useful informative signal about the cardiovascular system status, since it is a non-intrusive technique which is able to assess the body's vibrations due to its cardiac, and respiratory physiological signatures.

Apart from representing the outcome of the electrical stimulus to the myocardium - which may be obtained by electrocardiography - the ballistocardiograph has additional advantages, as it can be embedded in objects of common use, such as a bed or a chair. Moreover, it enables measurements without the presence of medical staff, factor which avoids the stress caused by medical examinations and reduces the patient's involuntary psychophysiological responses.

Given these attributes, and the crescent number of systems developed in recent years, it is therefore pertinent to revise all the information available on the ballistocardiogram's physiological interpretation, its typical waveform information, its features and distortions, as well as the state of the art in device implementations.
\end{abstract}

Keywords: Ballistocardiography, biomedical measurements, cardiac signal analysis, cardiovascular system monitoring, unobtrusive instrumentation.

\section{INTRODUCTION}

Ballistocardiography (coined from the Greek, $\beta \dot{\alpha} \lambda \lambda \omega$

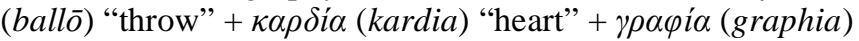
"description") is a method for obtaining a representation of the heart beat-induced repetitive movements of the human body, occurring due to acceleration of blood as it is ejected and moved in the large vessels. Ballistocardiography measures mass movements (here, the term mass movements refers to both the mass of circulating blood and to the heart itself during the cardiac cycle [1-3]) of the body, generated by the forces associated with heart contraction, informing about the overall performance of the circulatory system.

The pioneering works in the field of ballistocardiography are credited to Gordon in 1877 [4] and Henderson in 1905 [5], but the members of the Committee on Ballistocardiographic Terminology, and specially its chairman Isaac Starr, are considered to have been the founding fathers of the field, by publishing the first scientific works on it [6-8], and continued high-impact investigations and discoveries for decades [1].

The device Starr used was quite similar to the first ballistocardiographs [2], and served as inspiration to the ensuing. All of them were based on suspended tables where the subject lied. These devices from mid XX century, the

*Address correspondence to this author at the Instituto de Telecomunicações, Instituto Superior Técnico, Torre Norte piso 10, Av. Rovisco Pais 1, 1049-001, Lisboa, Portugal; Tel: +351 2184184 54; Fax: +351 2184184 72; E-mail: eduardo.pinheiro@1x.it.pt golden age of ballistocardiography, were labelled: "high frequency" [8], "low frequency" [9], and "ultra-low frequency" [4, 5, 10-14]. Only in 1949 Dock's "direct body" [15-19] inaugurated the use of a different measurement process, although it kept the traditional table-based apparatus typical of every ballistocardiograph at that time.

Two main problems were open during the early developments of ballistocardiography, the physiological interpretation of the signal and its deformations [2, 3, 20-39], and the improvement of the device, so that the mechanical limitations regarding the vibration ceased to influence the recordings [2, 39-45]. The second was a very hard task, given electronic and mechanic restrictions on the available technology. Normalization was an important matter as well [46-49], emerging as a necessity given the increasing number of studies published, all based on different devices and nomenclatures, and their important implications for the field [20-39]. Ballistocardiographic spatial axes and conventions for polarity were instituted by the American Heart Association's Committee on Ballistocardiographic Terminology [48].

Ballistocardiography was comprehensively studied to confirm its significance as a cardiological examination, as it happened with electrocardiography, fluoroscopy or radiology. Only ballistocardiography failed in proving its broad usefulness, and it did not started being employed routinely [3]. Some diagnostic procedures do not achieve generalized usage due to a series of factors. Economic reasons, difficulty in clinical application, its specialized nature, and the value of its input may be cited. Some of these 
factors lead to a progressive cooling of the initial enthusiasm on ballistocardiography, although much hope and appraisal had been given to it, as one can read in Gubner's 1953 text [3] “(...) it may be remarked that the ballistocardiogram provides, in simple and routinely applicable fashion, a considerable body of useful information not otherwise obtainable; and hence fulfils the criteria of a valuable adjunct in examination of the heart."

Nowadays, the technological developments in the biomedical and electrical engineering fields pledge to bring new developments to ballistocardiography. The interest in this signal is renewed because of the new demands and trends on home e-health systems, namely unobtrusiveness and ubiquitous computing [50-52]. Being able to unobtrusively assess the body's vibrations due to the cardiac and respiratory physiological signatures is potentially of utmost impact in current e-health systems, as it allows embedding the ballistocardiograph in the environment, as well as performing the measurements without medical staff presence, factors which together reduce the examinations' stress and the patient's psychophysiological responses [53].

From the early ballistocardiographic implementations, tracking the movement of the special bed on which the patient laid, to now several other methods have been introduced, e.g., static charge-sensitive bed [54], and body mould bed [55]. But the majority of recent applications have been centred in electromechanical film (Emfi) sensors [56, 57], embedding it in chairs, and gathering the signal from its backrest, seat, or both [58-62]. New digital data processing methods, focused uniquely on the ballistocardiogram signal, gathered from the piezoelectric Emfi sensor, have been subjected to insightful investigation [63-70].

Therefore, in addition to the general purpose developments in analogical and digital signal processing, knowledge has been produced directly focusing the ballistocardiogram signal processing problem. Under this work frame, some physiological studies have been produced $[58,61,69,70]$, and as the sensing and processing techniques keep evolving, much more multilevel biomedical knowledge is ought to be available.

This paper firstly presents the main characteristics of the ballistocardiogram and the foundational aspects of this field, presently subject to renewed attention. Subsequently modern ballistocardiograph implementations are reviewed, underlying the most recent developments and pointing out their most interesting capabilities, and how they may be implemented and integrated in modern home health care environments to the benefit of both the frontend patient and the medical staff.

\section{CLINICAL VIEW}

Evaluating cardiovascular function without cardiac catheterization has been subject to various approaches by using non-invasive devices: apex cardiography, ballistocardiography, impedance cardiography, phonocardiography, and the foremost case of electrocardiography [71]. With the technological progress sophisticated solutions as M-mode, two-dimensional, Doppler, and colour flow echocardiography, nuclear-based techniques, x-ray computed tomography, and nuclear magnetic resonance imaging, the need of invasive measurements has been diminished.
However, in spite of the various modalities contributing to a comprehensible description of a patient's state, the workload associated to most of these examinations is not compatible with the demographic evolution of world population, and the related raise in health care assistance needs [72].

Since the ballistocardiographic curves are recognized to show abnormalities indicating a failing heart [71], it will be described the clinical interpretation of BCG data.

\section{Ballistocardiogram Waves}

The Committee on Ballistocardiographic Terminology decided in the Scarborough-Talbot Report [48] to keep the terminology of the ballistocardiogram waves proposed by Starr et al. in [8]. The ballistocardiographic waves were hereafter named with the capital letters $G$ through $O$. The report reproduced a typical signal of each kind of device available in those days. It also compared those ballistocardiograms with simultaneously acquired electrocardiogram, phonocardiogram, and carotid pulse waveforms. Fig. (1) presents the nomenclature used by the abovementioned report. Fig. (2) depicts the acceleration, velocity and displacement ballistocardiograms, simultaneously obtained from a direct body system, having noticeable waveform differences and similarities.

The Committee on Ballistocardiographic Terminology established in the Scarborough-Talbot Report [48] the common names of these first devices, and presented the most important relations between the waveforms each produced. Starr's was named "high frequency" [8], Nickerson's "low frequency" [9], whereas "ultra-low frequency" or "aperiodic" was the name given to the devices developed by Gordon [4], Henderson [5], von Wittern [10], Talbot [11], Burger [12], and Rappaport [14], and "direct body" to the ballistocardiographs developed by Dock [19], Smith [15], Arbeit [16], and Walker [17].

From the results published up to 1956, the Committee was in position to make a quantity of comments regarding the expected waveform delays and relations of the ballistocardiogram. Most of these considerations will be described below, and illustrated by representative waveforms, Fig. (3) incorporates in the exemplifications the output of an ultra-low frequency system.

\section{BCG Genesis}

The ballistocardiogram waves may be separated in three major groups, the pre-systolic (frequently disregarded), the systolic and the diastolic. The I and $\mathbf{J}$ waves are also referred to as ejection waves.

\section{Pre-Systolic Group}

- F wave: (rarely seen) headward wave preceding G, related to pre-systolic events, not an after-vibration.

- G wave: small footward wave which at times precedes the $\mathrm{H}$ wave.

\section{Systolic Waves}

- H wave: headward deflection that begins close to the peak of the $\mathrm{R}$ wave - maximum peak synchronously or near the start of ejection. 

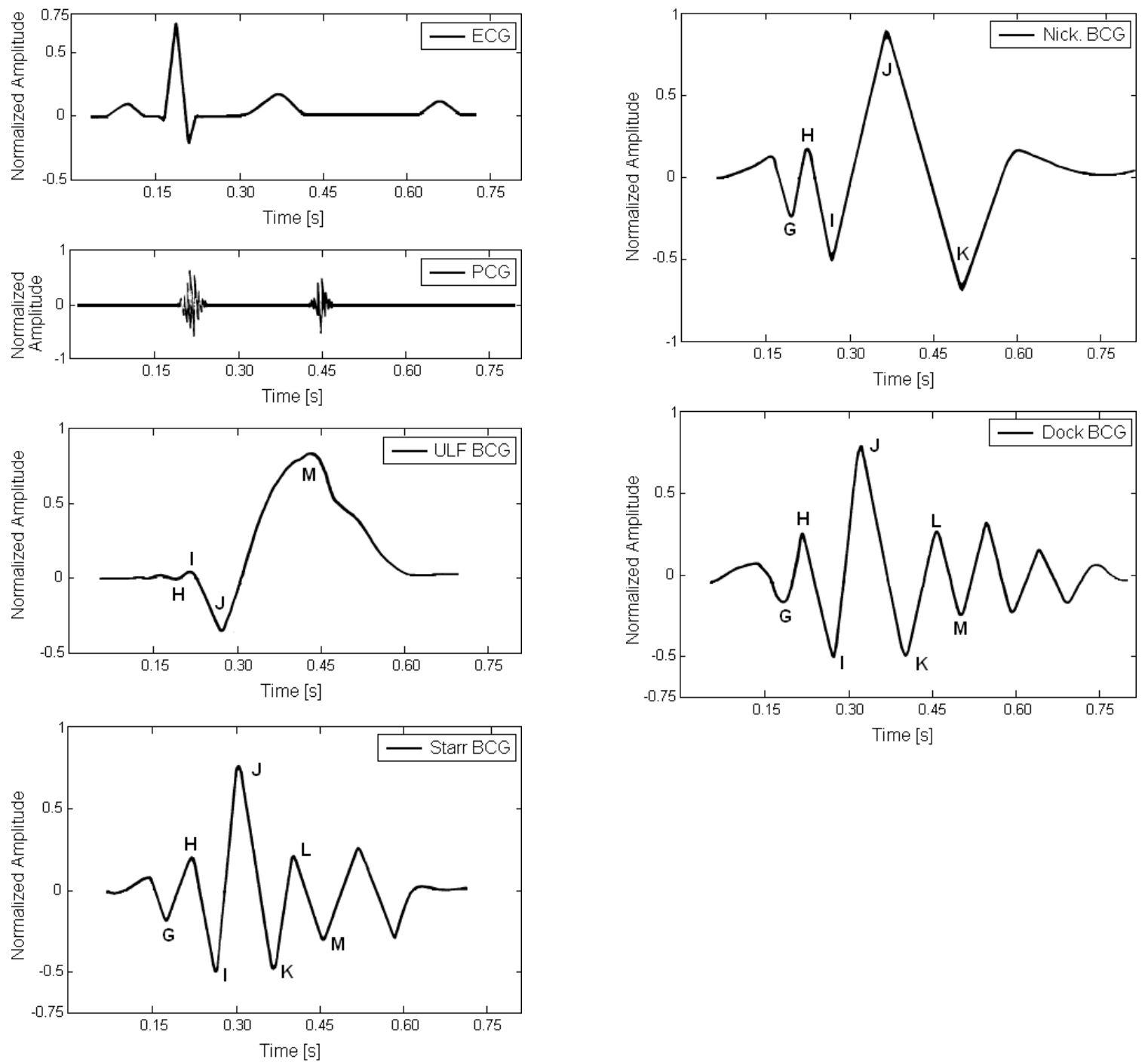

Fig. (1). Depiction of typical displacement records from different ballistocardiographic systems shown to illustrate differences in timing of waves and relationship between them and the electrocardiogram and phonocardiogram. In descending order: electrocardiogram, phonocardiogram, ultra-low frequency ballistocardiograph [4, 5, 10-14], Starr's ballistocardiograph [8], Nickerson's ballistocardiograph [9], and Dock's ballistocardiograph [15-19].

- I wave: footward deflection that follows the $\mathrm{H}$ wave occurs early in systole.

- J wave: largest headward wave that immediately follows the I wave - occurs late in systole.

○ K wave: footward wave following $\mathrm{J}$ - occurs before the end of systole.

\section{Diastolic Waves}

$\circ \quad \mathrm{L}$ and $\mathrm{N}$ waves: two smaller headward deflections which usually follow $\mathrm{K}$.

- M wave: footward deflection between $\mathrm{L}$ and $\mathrm{N}$.

- Smaller subsequent waves may be visible, and are named in sequence.

This type of relative referencing, with several waves related to the $\mathrm{H}$ component of the ballistocardiogram denotes the importance of this wave, which in [73] was found to be nearly synchronous with the first heart sound and the apex thrust.
A healthy subject is expected to have a ballistocardiographic record similar to the ones presented in preceding Figs. (1 and 2). The H, I, J, K, and L waves should be dominant and forming a $\mathrm{W}$ shape, with the diastolic components being smaller, and there should not be any marked notching or slurring of the individual waves [74]. In spite of having such a typified waveform, rarely are all the non-systolic components perceptible. Furthermore it is very easy to produce artefacts, either by the device's architecture [41], or by any form of patient movement, as well as by respiration itself. In some cases, marked respiratory variation affects a minimum of complexes. However, this should not necessarily be considered abnormal, because flabby abdominal musculature, loss of compliance on the great vessels or emphysema may be a determinant factor in some of these cases [19].

\section{Sources of Distortion}

Any movement of mass within a body, sustained without constrains, will be reflected by oppositely directed motion of 

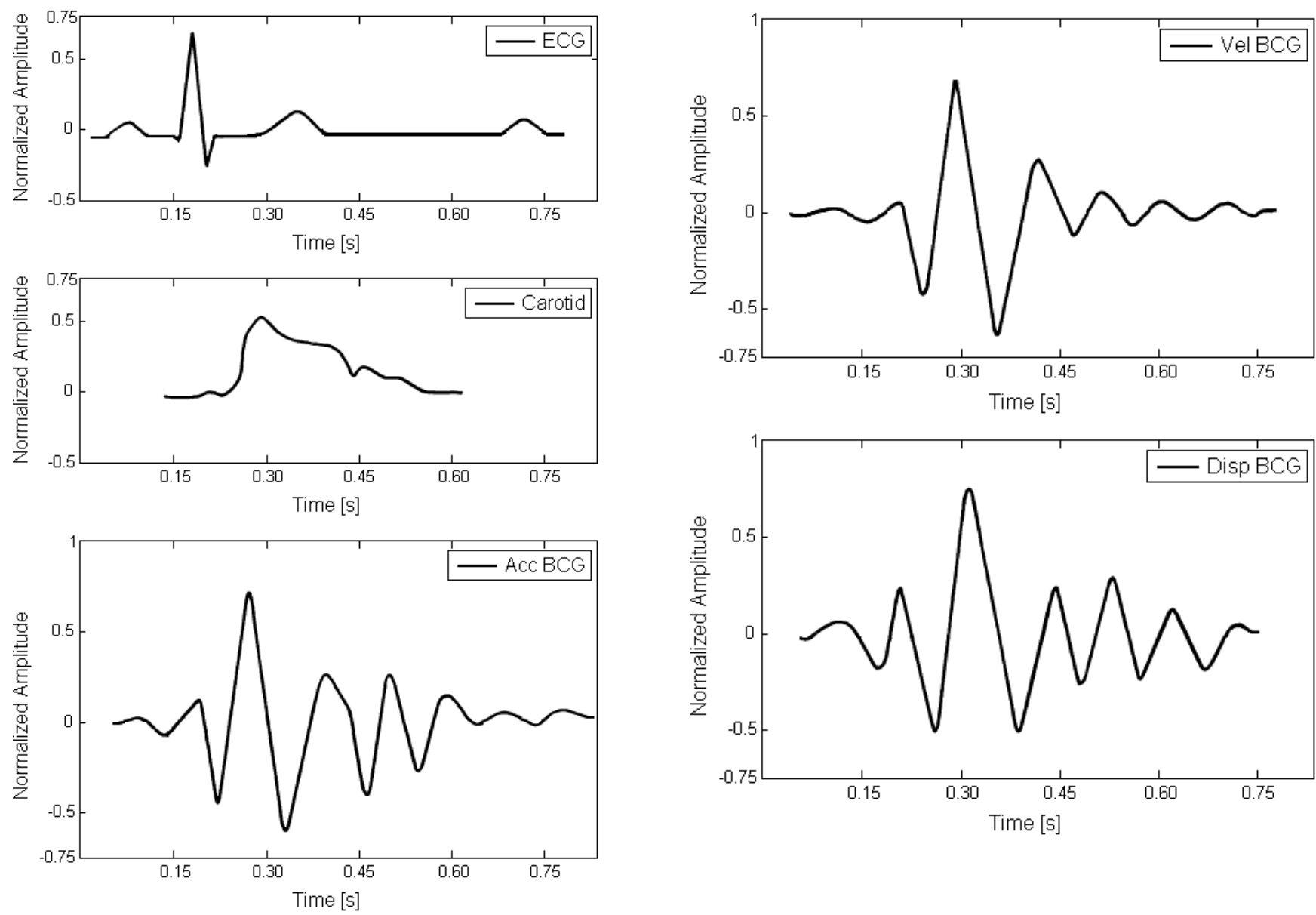

Fig. (2). Depiction of the typical waveforms obtained from a direct body system showing the relationship to the carotid pulse, and electrocardiogram. In descending order: electrocardiogram, carotid pulse, acceleration ballistocardiogram, velocity ballistocardiogram, and displacement ballistocardiogram (adapted from [48]).
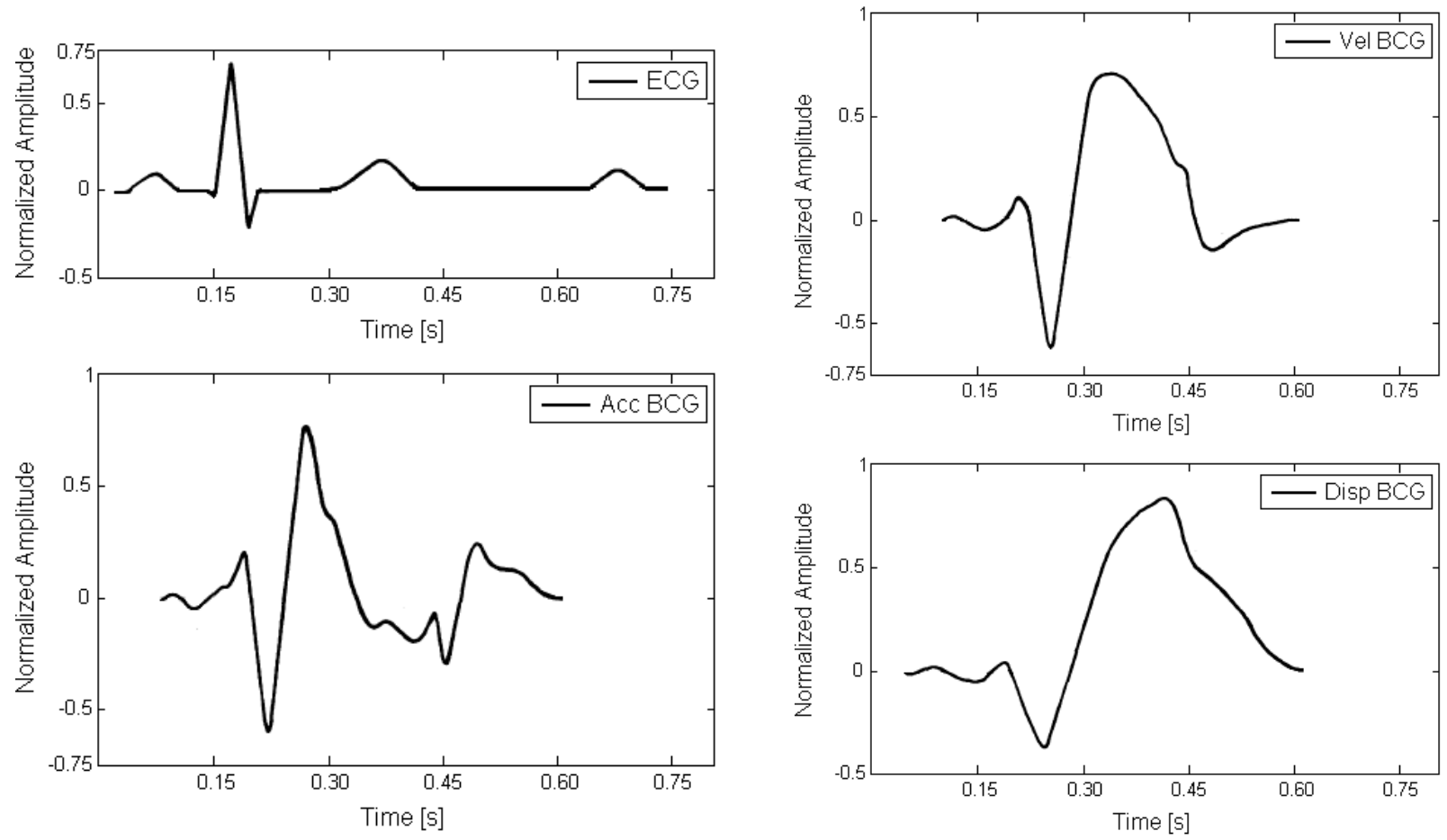

Fig. (3). Depiction of the typical waveforms obtained from an ultra-low frequency system showing the relationship to the electrocardiogram. In descending order: electrocardiogram, acceleration ballistocardiogram, velocity ballistocardiogram, and displacement ballistocardiogram. 
the body itself, conserving the system's centre of gravity unaffected. This is the primary physical principle of ballistocardiography, Newton's third law of motion. Such rule implicitly justifies the large number of factors generating artefacts [41-44]. The artefacts observed in ballistocardiography are chiefly related to patient motion, and complementary causes are unavoidable limitations in the device mechanical architecture, for instance sensor bandwidth limitations, or platform resonance. However, leaving device mechanics to the proper section, distortion of the ballistocardiograph output may occur due to any of a number of simple events, from breathing to posture changes, even with a seemingly calm and still patient.

Patient motion is associated with ballistocardiogram baseline drifts, and it is a serious problem, since that dislocating the body greatly exceeds the amount of the naturally vibrating mass the device aims to record. Regarding baseline drifts, interesting observations were made by Scarborough [48], stating that a reasonably flat baseline is often seen in late diastole - when the body's oscillations are minimal or have ceased - and that, usually, flat baseline is not achieved because the motion of the body and bed-type supports never ceases. Therefore, diminishing patient motion will help stabilize the baseline, although it is unavoidable that some wandering will occur.

The $\mathrm{H}$ and $\mathrm{J}$ waves are distorted due to halted breathing. Local turbulence in the carotid artery obscures the close relationship between the carotid pressure pulse and the left ventricular waves of the ballistocardiogram. Hence, the amplitude and contour of the $\mathrm{J}$ wave may be changed by non-cardiac factors, since the contour of the arterial pressure pulse is profoundly affected by such factors as walls' compliance and blood's dynamic viscosity [75]. Apart from changing the ballistocardiogram shape when it is stopped [75], respiration also influences the right ventricular ejection $[76,77]$. Consequently, normal breathing modifies the amplitude of the ejection waves, which is visible in practically all publications. Therefore, a healthy subject, without moving, and producing a normal ballistocardiogram, will not be able to produce a beat by beat repeatable pattern, even if he accurately controls his respiration.

Regarding the respiration effect, a simplified scheme of grading the ballistocardiogram has been employed by [32], placing emphasis on respiratory variation, by identifying four grades of ballistocardiographic abnormality:

1) Regularity of complexes is preserved. Inspiration amplitude is normal, but in expiration decreases and varies in definitiveness.

2) Half or more of the complexes are abnormal, mainly in expiration, and the inspiratory amplitude is decreased to some extent.

3) Complexes are identifiable but abnormalities are present in inspiration and expiration phases.

4) All the waves are unidentifiable and of low amplitude.

Smoking also causes changes on the ballistocardiogram, for instance, an elevated percentage of coronary vessel disease patients deform their ballistocardiogram after smoking a cigarette [78]. The abnormalities found in a positive cigarette test are non-specific, but large diastolic waves are commonly observed. Proposed theories pointed at coronary and generalized arteriolar vasoconstriction and direct myocardial effect [74].

\section{Physiological Associations}

The foremost features and physiological results available on the interpretation of ballistocardiographic waves are subsequently presented. Although the ECG is the most wellknown electrophysiological signal, phonocardiography was proved to offer better time synchronization to the beginning of mechanical systole and diastole than the electrocardiogram [79]. Therefore, it is the most excellent reference for analysing the physiological relations of the ballistocardiogram waves. The following Fig. (4) depicts a combined image of the synchronisms observed from the ballistic waves with apex cardiography (ACG) and phonocardiography (PCG).
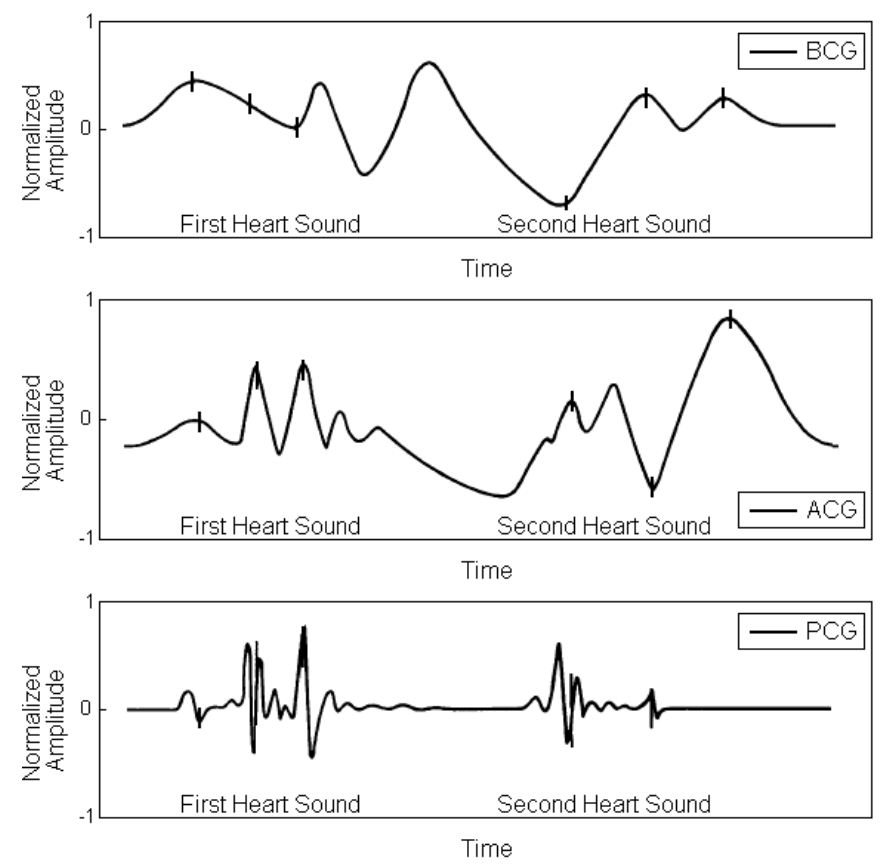

Fig. (4). Composition showing ballistocardiogram, apex cardiogram, and phonocardiogram (in descending order).

A number of studies [24, 73, 79-91] used PCG together with other techniques and physiological elements to improve the physiological interpretation of the ballistocardiogram, with [91] being an important mark, as it was the first study to report the $\mathrm{F}$ wave.

Nevertheless, the cardiovascular analysis regarding the origin of the ballistocardiogram waves is complicated, since there are different studies reporting distinct conclusions. The most critical example is the difference between Gubner et al. [3], a February 1953 Circulation article, and the following month's publication of a study from Thompson's team [91]. These studies have significant divergences, given the different devices employed. Both of them are valuable: as Gubner [3] deeply reflects on the major waves while Thompson [91] analyses all the ballistic waves. However, the Committee on Ballistocardiographic Terminology did not 
comment these divergences in the Scarborough-Talbot Report [48], published in Circulation September 1956.

\section{Both Views are Congregated in the Following Synthesis}

F Wave: This wave is a positive deflection before the $\mathrm{G}$ wave [92], and it is originated by atrial contractions [91]. It is seen mostly if the heart rate is slow, and occurring simultaneously with the auricular sound, between the electrocardiographic $\mathrm{P}$ and $\mathrm{Q}$ waves, and also coinciding with the atrial wave of the apex cardiogram [91].

- G Wave: This wave is a downward deflection previous to the ballistic $\mathrm{H}$ wave, and it is associated with atrial systole [3], as it follows the $\mathrm{P}$ wave and precedes the QRS complex. It is seen frequently, particularly in subjects with bradycardia, or with heart block [73], where it may be observed more distinctly due to the dissociation of atrial and ventricular contractions [3]. The observations reported in [86] showed the presence of $\mathrm{G}$ wave related to the third component of the first heart sound, at the time of the second positive deflection in the apex cardiogram, and at the onset of the surface carotid pulse which is the opening of the semilunar valves and the beginning of mechanical ventricular systole.

- $\mathrm{H}$ Wave: This wave is a somewhat slow positive deflection preceding the commencement of an abrupt downstroke, the I wave. The duration of the $\mathrm{H}$ wave is inferred in [3] to reflect the duration of the isometric or presphygmic period of ventricular contraction.

It was first defined as occurring simultaneously with the first heart sound's fourth and last component [91, 93, 94]. It was as well found coincident with the second negative deflection, on the descending slope of the negative wave or the rise of the systolic plateau in the apex cardiogram [94]. However, using high speed and reduced lag recording methods, another study stated instead that the $\mathrm{H}$ wave begins after the onset of electrical activation of the ventricles and before the first component of the first heart sound, and that this wave terminates with the end of the first heart sound [3]. The last component of the first heart sound was endorsed in $[91,93]$ to the acceleration of blood in the great arterial vessels during the ejection phase of ventricular systole.

The theory of $\mathrm{H}$ representing a force produced by both atrial contraction and the apex thrust [73], is contradicted in [3], providing as an explanation for the $\mathrm{H}$ wave the reflection forces associated with abrupt deceleration in the flow of blood returning to the heart. With the sudden rise of intraventricular pressure accompanying the onset of systole, blood flow into the ventricles is abruptly halted and this sudden deceleration is reflected in the $\mathrm{H}$ wave. These conclusions are possible because of the diverse heart sounds analysis.

The end of the $\mathrm{H}$ positive deflection is marked by an abrupt downstroke, the I wave, which represents the onset of ejection.
I Wave: The I valley is a sharp negative deflection, occurring early in systole. It appears at the end of the fourth component of the first heart sound, and ends with the coarse vibrations in the apex cardiogram, which denote systolic activity. Or, in a different apex configuration, this may occur at the end of the maximal ejection phase [83]. This wave occurs simultaneously with the anacrotic notch of the surface carotid pulsation, being at times slightly delayed, but always preceding the peak of the surface carotid pulse [91]. The same happens with the onset of incisura, which is subject to a similar variation caused by respiration or phase displacement. The start of the femoral surface pulse is hardly coincident with the I wave [28, 91].

According to [3] the ballistic I wave, a sharp negative deflection, marks the start of ejection, and represents the footward retreat of the body provoked by the acceleration of blood both into the pulmonary artery, and in the ascending arch of the aorta.

$\mathrm{J}$ Wave: The $\mathbf{J}$ peak is a positive deflection, also related to blood ejection. It does not show an unambiguous relationship to the apex cardiogram, roughly with the tip of the carotid and abdominal aortic pulsations. From phonocardiogram analysis it occurred with the ample vibrations in early systole [91]. The J deflection is usually associated with the ascending slope of the femoral pulse. Regarding the analysis of [3], after the upward movement of the accelerated blood, its impact on the crown of the two aorta arches abruptly reverses the direction of the forces generating the quick recoil of the body in the headward direction, the ballistic $\mathrm{J}$ wave.

A great deal of ballistocardiographic literature references attempt to calculate the cardiac output from the amplitudes and areas of the IJ pair, as they are clearly related to ventricular ejection. The amplitude of the I and $\mathbf{J}$ waves is correlated with the cardiac output [8, 95-98], but it exists less dependence on the cardiac output than on velocity [3], and the ballistocardiogram is more related to heart's force than with output [99]. As both ventricles contribute in comparable proportion to the blood flow hastening, their contribution to the ejection waves is in almost equal measure [99], but respiration's influence solely on the right ventricle makes its ejection swing during respiration [76, 77], resulting in an increase in the $\mathbf{J}$ wave amplitude with inspiration [3].

- $\mathrm{K}$ Wave: $\mathrm{K}$ is a footward wave with its onset at the peak of the $\mathrm{J}$ wave and extending itself, with a relatively steep slope to a deep trough at a level similar to the depth of the I wave. The ballistic K wave is synchronized with the second heart sound's second component [93], which is due to the semilunar valves' closure. In [91] the $\mathrm{K}$ wave was found to coincide with the descending slope of the femoral pulse, whereas synchronization found in [28] was with the peak of the femoral pulse. Other discrepancy was the simultaneity of the carotid pulse's dicrotic notch and the peak of the $\mathrm{K}$ wave. 
In the results of [3] the low of the $\mathrm{K}$ wave normally preceded the onset of the second heart sound, thus resulting in a coincidence with the peak of the femoral pulse curve, as [28] reported. This wave is wholly due to systemic circulation, in concrete, deceleration of blood by the peripheral resistance in the descending aorta [24], and reduction of ejection velocity at the end of systole. Its depth is related to the length of the descending aorta, as coarctation of the aorta showed [25, 29, 30].

L and M Waves: these two waves are related to events occurring during the diastole. At times abortive $\mathrm{L}$ and $\mathrm{M}$ waves can be found, whereas at other times a prolonged $\mathrm{K}$ peak is observed, or even a regular $\mathrm{K}$ wave is observed while $\mathrm{L}$ and $\mathrm{M}$ waves are still absent. When visible, in the [91] experiments, the $\mathrm{L}$ wave coincided in temporal positioning with the fourth component of the second heart sound [93], which is the opening of the atrioventricular valves. This is corroborated by the simultaneity with the negative deflection $\mathrm{O}$ present in the apex cardiogram, between the peak caused by the closure of the semilunar valves and the peak of the rapid filling wave [84].

However, L and the succeeding diastolic waves are presented in [25] as representing aorta forces with intricate origin in a number of circulatory phenomenons [3].

- N Wave: This wave was found to occur synchronized with the third heart sound and with the peak of the rapid filling wave [74], a brief delay sometimes noticed was due to device design issues.

A publication dated of 1957 provides another look at the ballistocardiographic waves with even a higher detail [75], by applying an ultra-low frequency device [100]. Hence, the resolution of the obtained results is very similar to the available nowadays. This publication discusses a multiplicity of points, because it decomposes the major waves into several segments. This analysis is too broad to be reported here, however, it constitutes a significant bibliographic reference. The $\mathrm{H}$ and $\mathrm{J}$ wave changes in the ballistocardiogram of a normal subject, after respiration is halted, were first reported in this study.

\section{Clinical Interest}

Ballistocardiography is an accurate indicator of the heart's age, much better than the chronological age of a person. Furthermore, diseases related to heart contractility are also correctly prognosticated by this signal, long before any symptom manifests. On the other hand it is hard to establish a univocal relation between a disease and the BCG disturbances it induces.

\section{Age}

The number of ballistocardiographic patterns considered abnormal, i.e. above the defined grade 1 (as defined in the section Sources of distortion), on a priori normal individuals increases directly with aging, as several studies on numerous groups demonstrate [26, 36, 101-105]. Franco [102] reported that more than 50 percent of ballistocardiograms, of 317 normal individuals (without any evidence of cardiovascular disease, whose ages ranged from 35 to 64), were found abnormal. It is unlikely that Franco's ballistocardiograph was wrong. The BCG was hinting the development of disease.

A 20-year 211-person follow-up of Starr [106], condenses the previous assertions and introduces quantitative importance to ballistocardiogram analysis, thus deserving an extended citation from the conclusions section: “(...) Hearts contracting with little force at the initial test later suffered from death and cardiac disability, chiefly coronary heart disease, in far greater numbers than those whose hearts contracted strongly. The amplitudes of ballistocardiograms, strongly correlated with the later development of heart disease and also strongly correlated with the ages of the subjects. [The amplitude-age correlation coefficient was 0.74 , values of 0.25 being significant for $\mathrm{p}=0.01$ ] Hence, the heart tends to weaken and beat with less coordination as it grows older", concluding “(...) those who later developed heart disease had initial ballistocardiograms that averaged 25 percent smaller than those of their mates who remained healthy for the next 17 years".

Therefore, those who later developed myocardial disease had, in the initial test, their hearts beating like the ones of much older normal people, that is to say, their hearts "physiologic age" far exceeded their chronologic age.

The above mentioned studies demonstrated that the risk of development of coronary heart disease is strongly dependent upon age, but equally strongly dependent upon the wave form of the ballistocardiogram. Moreover, the likelihood of recurrences, for patients already manifesting coronary heart disease, is predicted by the ballistocardiogram waveform, regardless of the patient's age.

\section{Abnormal Ballistocardiograms}

The amplitude of the ballistocardiographic waves is determined mainly by cardiac output, cardiac force, and the velocity of ejection, explaining the original purpose of Starr of estimating cardiac output [8].

However, one compromising example to this intent is shock, where the arterial blood volume is substantially reduced, while both the velocity of ejection and the aorta blood flow increase. In this case, the ballistocardiogram ejection waves present values of stroke output quite larger than the actual output assessed by the Fick method [107109].

A significant study, from Moser [34], analysed 100 subjects recovering after myocardial infarction, registered 81 abnormal and 19 normal ballistocardiograms. In this study, the electrocardiogram was also assessed, with 74 subjects of the abnormal BCG group presenting abnormal ECGs as well. On the other hand 17 of the normal BCG group had an abnormal ECG.

Abnormal ballistocardiograms are obtained in case of acute myocardial infarction, angina pectoris, and in asymptomatic coronary artery disease, being an early indicator of future complications [3, 106]. Namely in elders, abnormal ballistocardiograms are an important warning [106]. 
A study from Dock [104], reported that $92 \%$ of 152 angina patients had an abnormal ballistocardiogram. Relevant results were published by Scarborough in [110], a study including 191 angina patients, reporting that $75.4 \%$ of them had abnormal ballistocardiograms, with increasing incidence in the older age groups.

The study of drug's effects on cardiac function may be carried out by observing the ballistocardiogram $[95,111]$, as it was done in the past. In fact, the investigation of a number of agents and situations was performed reporting BCG alterations: digitalis [112], quinidine [113], epinephrine [114], sympatholytic agents [38], visammin [114], nitroglycerin, among other nitrites [115], nicotine [116, 117], as well as surgery, and changes in blood volume [118].

Smoking changes the ballistocardiogram, for instance, patients with coronary vessel disease are likely to present deformed ballistocardiograms after smoking [78], which is induced by nicotine's effect $[116,117]$.

\section{Disease Effect on Waves}

The ballistocardiographic modifications that are observed in coronary diseases are not specific of this condition. Other disorders associated with impaired force of ventricular ejection will produce abnormalities of the same kind, such as slurring or significant amplitude decreases of the I and $\mathrm{J}$ waves.

The ballistic waves' investigation appears to be very pertinent regarding coronary artery disease. Despite all the limitations imposed by the exam's sensitivity, several investigators regard its findings as very worthy [3].

Impressive results were found on the coronary heart disease predicted by the ballistocardiogram, namely regarding the appearance or recurrence of myocardial ischemia [105].

Malfunctioning of heart valves influences the ballistocardiogram, by virtue of their ejection influence, contributing to the development of myocardial failure. Following coronary occlusion, the recording of normal ballistocardiograms indicates that the myocardium's contractile mechanism is restored [3].

Mitral stenosis decreases the amplitude of the I and $\mathbf{J}$ waves, while aortic stenosis and insufficiency increases. However, mitral valvular disease does not produce a specific modification on the ballistocardiogram [3].

Coarctation of the aorta is the medical condition, among the congenital heart defects group, most often prognosticated with the ballistocardiogram, as several different studies corroborate that most cases of coarctation have a diminished or inexistent $\mathrm{K}$ wave $[25,29,30,119]$.

Patent ductus arteriosus, Eisenmenger's complex, hypertension, arteriosclerosis, and interatrial septal defect have also been reported to reveal a diminished $\mathrm{K}$ wave [119, 120]. Therefore, this effect is likely to be detected for coarctation of the aorta, but it is not exclusive.

Constrictive pericarditis [62], arteriovenous aneurysm, rheumatic heart disease and congestive heart failure [11], [27], and abnormalities in return flow and cardiac filling in general, affect the diastolic $\mathrm{H}$ and $\mathrm{L}$ waves, as well as posterior waves. Patients with coronary vessel disease may present resembling deformations in the ballistocardiogram after smoking [78].

Myocardial infarction, angina pectoris and asymptomatic coronary artery disease are likely to induce abnormal ballistocardiographic records $[3,34,104,110]$. Patients already manifesting coronary heart disease, have the likelihood of recurrences predicted by the ballistocardiogram waveform [106]. The risk of developing coronary heart disease is strongly dependent both on age and the morphology of the ballistocardiogram.

\section{DEVICES}

Ballistocardiography is now being rediscovered, but an important history, with hundreds of publications and studies, is ought to be considered. Current devices are implementing ideas which would seem impossible to the pioneers of the field, but share common grounds with earlier implementations. The most important characteristics and improvements of both antique and contemporary ballistocardiographs are subsequently revised.

\section{Early Developments}

Early ballistic cardiography devices registered the forces exerted in the longitudinal axis of the body. Afterwards some alternative approaches were studied, such as lateral plane [121], and multidimensional vector registration [122-124]. Nevertheless, only the longitudinal measurement technique prevailed to our days. The waves recorded by this method are not pure forces, instead they are the projection of the vector sum of the forces due to heart activity. This vector may reflect forces associated with events in the early systole of the following cycle, thus making unattainable a perfect correspondence between forces, events and waves, especially when heart rate is fast, which favours superimposition of waves. Furthermore, the forces generated are transmitted through the soft tissues and skeleton to the sensing device, so the flexibility of the body structures, together with the natural period of body movement, leads to further modulation of the ballistocardiographic waves.

Starr developed a spring-coupled undamped table, with a natural frequency of $9 \mathrm{~Hz}$ [8], later baptized high frequency ballistocardiograph [48]. It did not suffered of baseline wandering due to such slow events as normal respiration, however this table also filtered events related to the cardiac cycle, causing other forms of ballistocardiogram distortion. Nickerson introduced a lower frequency, $1.5 \mathrm{~Hz}$, critically damped table [9], expanding the lower interval of usable spectrum, thus reducing the distortion of cardiac cycle waves, but being susceptible to the baseline variations induced by respiratory movements. The frequency response of this device was an improvement from the previous, albeit not being flat, so the traces wandering was diminished, but far from eradicated. The assumption of unison movement of both the table and the body was questioned by results published in [25], still this device was not overlooked at the time.

Obtaining ballistocardiographic registers directly from the body, without using a suspended table, while the subject is in supine position, was found possible by Nickerson [9] and Hamilton [25]. Both acquired the relative movements of 


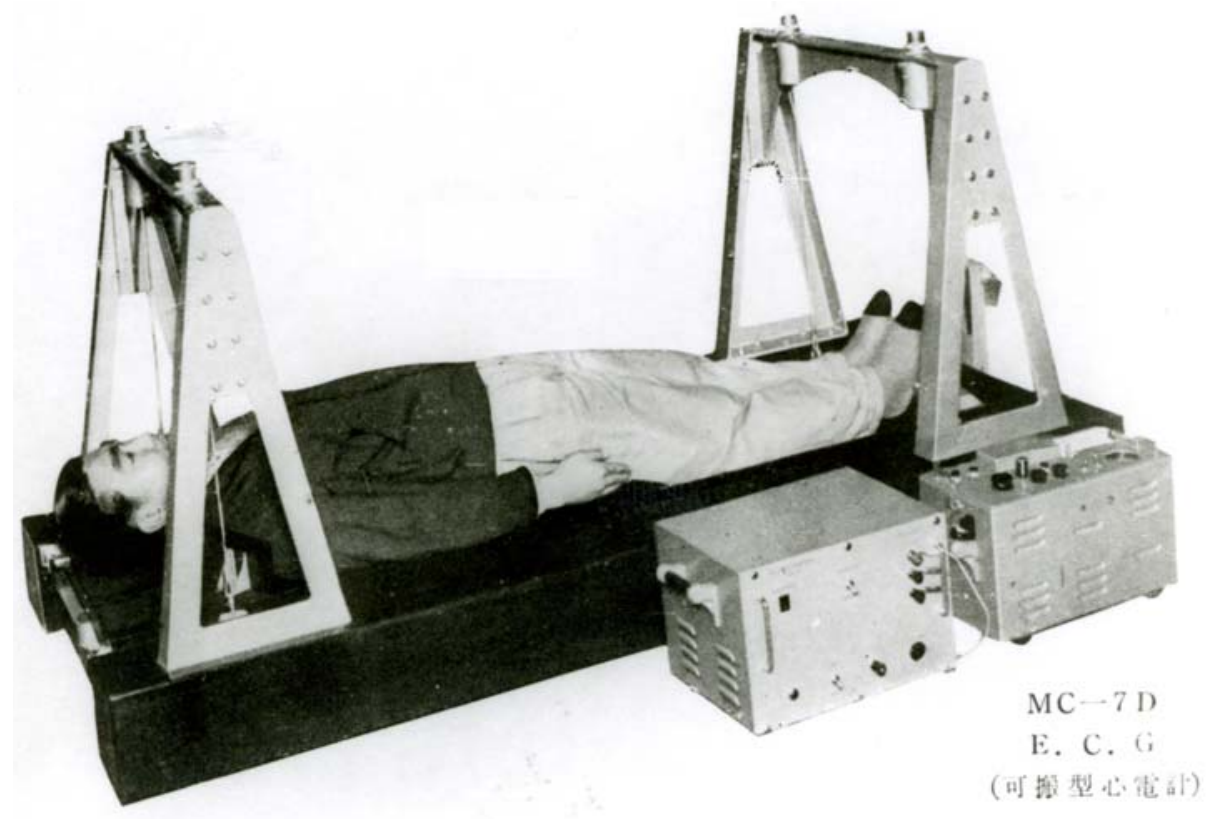

Fig. (5). MB-1 Ballistocardiograph, image courtesy of Nihon Kohden.

the head's vertex and a rigid table or where the subject was laid. From this rigid support, Dock and Taubman developed photoelectric and electromagnetic methods for measuring the relative movement between the table and a bar placed in the subject's shins [18]. Such method was simpler and more economical, while able to reduce distortion, if the signals were properly processed. The photoelectric sensor recorded displacement, whereas the electromagnetic one registered the velocity of body motion, with the shins being an appealing measurement site, as the orthopneic tremor was lower. The natural frequency that a subject, resting in supine position on a hard surface, possesses will change if head and heel support are added, especially due to the latter. It was observed that the type of foot support affects the ballistocardiogram components' magnitudes, damping and temporal position, being recommended the maximization of natural frequency and damping [44].

A last improvement was the piezoelectric ballistocardiograph introduced by Sheehan's team [125]. This sensing element, based on electric potential generation when subject to force, was made of barium titanate, with metal foils collecting the electrical charges appearing in the crystal's faces. Good coupling from the patient and the table to the sensor had to be ensured [44], while the electronic amplifier had to guarantee a frequency response that permitted the ballistic waves to be amplified equally.

During the establishment of ballistocardiography as a valuable exam, and when plenty of the key physiological, clinical and instrumentation aspects were yet undefined, the Japanese company Nihon Kohden already had started the commercialization of its MB-1 device, Fig. (5). This device, built in 1953, is far bigger than the system embedded in a chair, developed in this decade.

\section{Latest Developments}

After a period of relative abandon, the ballistocardiogram is now being rediscovered. The technological developments of the last century allowed the shrinkage of the huge ballistocardiographs previously described, to such a small size that they are presently inconspicuously embedded in office [58-61] and wheelchairs [62, 126], gathering the signal from their backrest, seat, or both $[58-62,126]$, as depicted in Fig. (6).
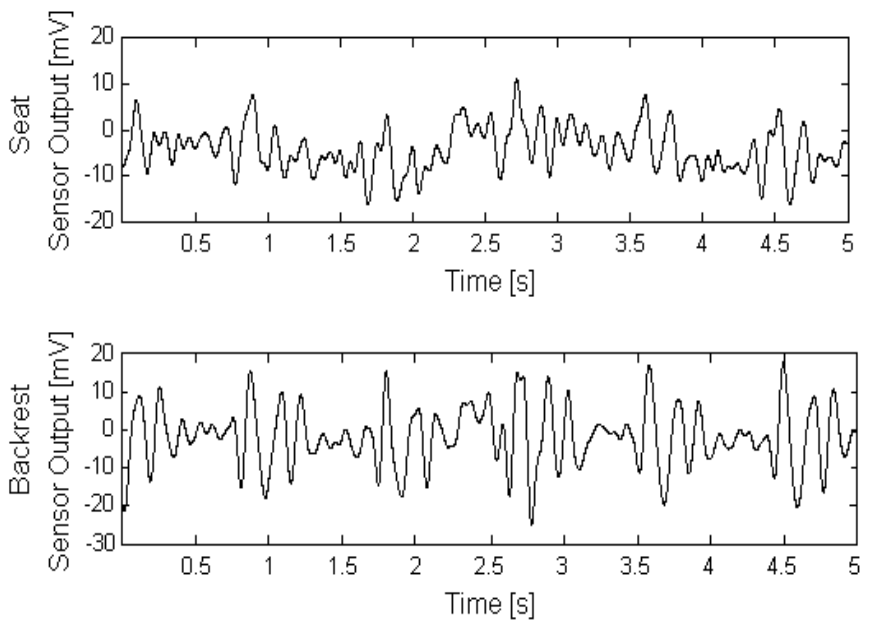

Fig. (6). Ballistocardiograms obtained from a chair's seat and backrest with the device of [126], with some fluctuations due to motion being noticeable. These two measurements spots give emphasis to different waves of the BCG. The backrest sensor highlights the ejection waves. The seat sensor outputs pre-ejection and ejection waves with similar amplitude.

Moreover, analogical and digital signal processing techniques improved the control of baseline wandering due to subject movement and respiration [62, 126, 127]. By means of wavelet decomposition [126], independent [127] and principal component analysis [128], respiration is perfectly isolated, and improvements on the ballistocardiogram are achieved, by identifying the components which are not due to physiological factors. 


\section{Chair-Based Systems}

Subsequently to the modern development of electromechanical film sensors $[56,57]$ three groups, the authors of [60-62], have been working more actively exploring this new approach to ballistocardiography. These sensors are piezoelectric film, composed of exterior homogeneous surface layers, with an interior composed of a number of thin polypropylene layers with air voids. When external forces are applied on the surface, the thickness and arrangement of the air voids is changed, thus producing movement of electrical charges. A charge amplifier is usually applied to output a voltage proportional to the force exerted [56].

Ballistocardiographic devices almost vanished, and nowadays, many cardiac signals with strong interest and well-established background are available, for instance, electrocardiography, impedance cardiography, and plethysmography. Even so, a manifest interest in developing ballistocardiography exists, due to the fact that this is the cardiac-related signal which, with least cost and simpler technology, can be acquired in a completely unobtrusive way. Current devices permit the acquisition of comprehensive cardiovascular system knowledge, without restricting the user, as they join respiratory and cardiac information, may use motion distortion to quantify the subject's level of activity [133], and, if a small photoplethysmographic sensor is allowed, also blood pressure estimation [61].

State of the art ballistocardiographic systems implemented in chairs unobtrusively gather additional biological parameters and signals. Embedding skin conductivity [58], or skin temperature [62], sensors in the chair's armrests, to allow deeper understanding of the patient's status, as Fig. (7) depicts. When the ballistocardiograph in not required to be completely inconspicuous, the addition of photoplethysmogram (PPG) and electrocardiogram (ECG) is of great benefit, because acquiring BCG, ECG and PPG allows computation of pre-ejection period, pulse transit time, and consequently pulse arrival time [61].

Systems based on wheelchairs have as goal the accurate assessment of the subject's respiratory and heart rate, when in regular movement in his daily activities. Although suffering strongly from artefacts, namely the heart rate obtained from I-I or J-J intervals, both these time features may be estimated, frequently recurring to wavelet decomposition of the signal $[62,126]$.

Advances in digital ballistocardiographic signal processing are mostly related to the chair-based implementation of BCG. The ballistic waves, gathered from the piezoelectric Emfi sensor, have been subject of insightful investigation [63-70], using neural networks, biortoghonal wavelets, independent component analysis, and innovative automatic clustering methods. These developments aim at an unsupervised segmentation and classification of ballistocardiographic waves, to estimate the abnormality grade of the chair user. The digital signal processing outcome is still limited, due to the signal's susceptibility to motion artefacts, and their volatile amplitude, because of the degree of freedom the user enjoys.

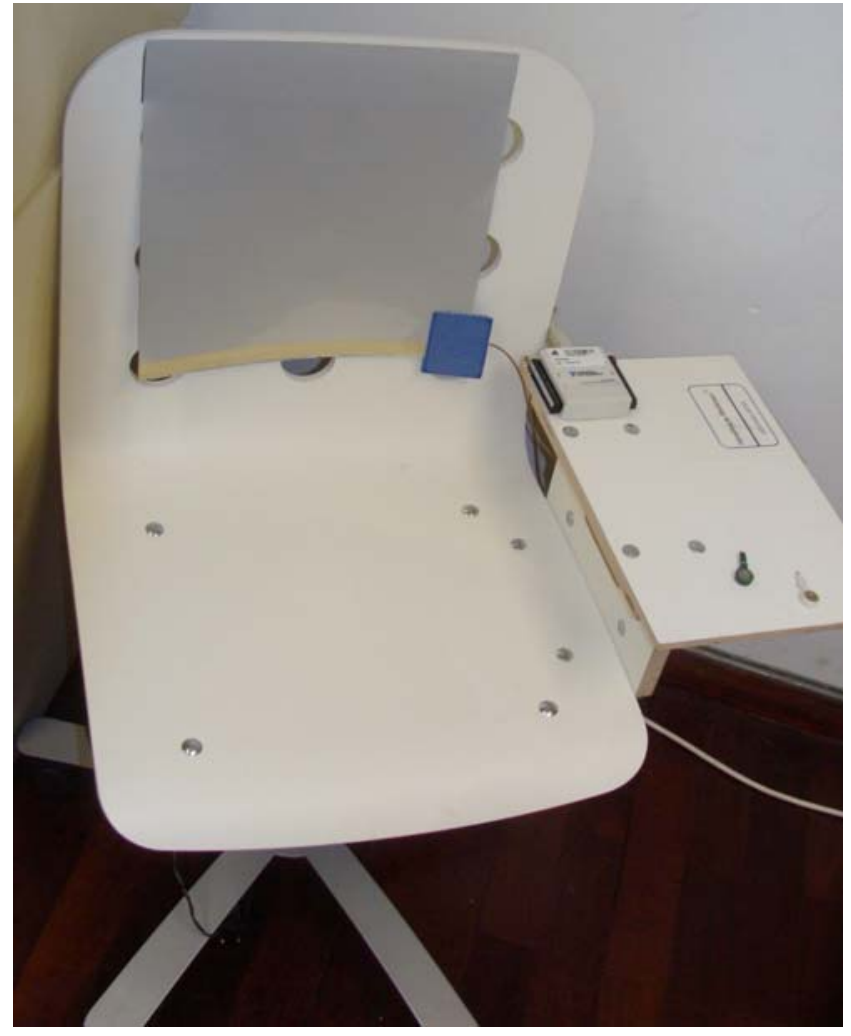

Fig. (7). Prototype described in [58], implementing skin conductivity and ballistocardiogram acquisition and processing.

Component analysis approaches were originally applied in the fields of electroencephalography and magnetic resonance imaging, where the ballistocardiogram is unwanted noise $[129,130]$. In these areas numerous methods have been developed to isolate the ballistocardiogram, for instance the dilated discrete Hermite transform [131], among several others available [132], but they have not been transposed yet.

\section{New Clinical Knowledge}

Physiological studies using the latest ballistocardiographic systems are now less concerned with the waves interpretation. Instead they look at expanding the ballistocardiogram use to the field of heart rate and blood pressure variabilities [61, 133]. Heart rate variability (HRV) is both an outcome and a diagnostic parameter for neurological maladies, due to the alterations induced by cardiac pathologies in the cardiovascular control mechanisms [134-137]. Blood pressure variability (BPV) is another parameter which presents significant indications regarding autonomic cardiovascular regulation [137]. In recent years, HRV and BPV have been increasingly studied in order to search correspondences between them and the existence of maladies associated with sympathetic and parasympathetic branches of the autonomic nervous system $[58,135,138]$. Both these variabilities carry prognostic indications in respect to cardiovascular risks $[134,136]$, and stress estimation from HRV.

Since a truthful assessment of the variabilities requires several minutes of recording, the unobtrusiveness of the ballistocardiograph makes it an ideal substitute for the 
electrocardiograph. Medical staff is not required to be present during the examination, and the only action to be made by the patient is being sat during a few minutes, hence not affecting his quality of living. Moreover, there are psycophysiological benefits by the use of this kind of method [53], and the frequency of the HRV evaluation may increase to a daily basis.

Considering the preliminary results presented in [61], if digital photoplethysmogram is added to the chair, BPV and systolic blood pressure may also be estimated from the pulse transit time [139, 140], the amount of time the blood takes to go to the periphery after being ejected [141]. Of course that, even if unobtrusiveness is not a requirement, the ballistocardiograph incorporation maintains its interest, as the ballistocardiogram processing in simultaneous with the electrocardiogram and plethysmogram allows the estimation of the pre-ejection period, pulse transit and pulse arrival times, thus having a more insightful characterization of the subject's cardiovascular control mechanisms.

\section{Other Sensing Advancements}

The chair ballistocardiogram, although an important trend in the present, is not the only approach to ballistocardiography currently under investigation. Special beds are still being patented [142-144], as well as other dissimilar approaches, e.g. a scale resembling device [145], or a more diverging pressocardiograph [146]. The development of sensors for sleep monitoring is the most active topic in embedded vital parameters' sensing, and a set of solutions have been proposed implementing sensor elements in beds. Generally piezoelectric are employed with the purpose of determining heart and respiratory rates [147156], but the ballistocardiogram signal itself is not analyzed, only the mentioned biological rates are extracted. However, in polysomnography studies, a number of new approaches and methods are being introduced, which may be interesting to fuse with ballistocardiography information, or apply as new sensors, to cite a few, the oscillosensor of [157], respiratory induced plethysmography [158], thoracic effort detector [159], or the pulse arrival time, an idea presented in the device of [160] and approached in the ballistocardiographic system of [61]. In 2007 one of the newest approaches was published, the implementation of Doppler radar technology to ballistocardiogram acquisition [161], which was recently compared with Emfi sensors using the topology presented in Fig. (8), [162].

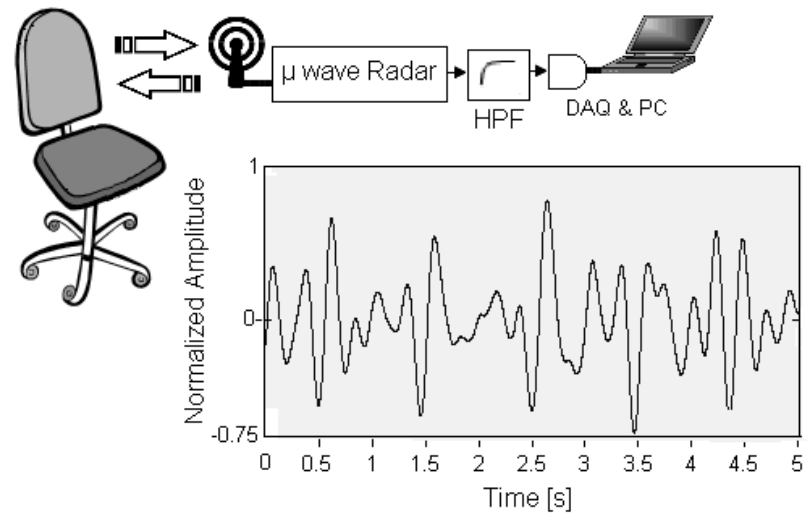

Fig. (8). Radar BCG system implemented in [162]. Block diagram and signal obtained for a healthy subject.

\section{SUMMARY AND CONCLUSION}

The new demands and trends on home e-health systems and ubiquitous computing, make the physiological signatures related with the ballistocardiogram of utmost impact in current homecare systems. The ballistocardiograph may be embedded in objects of common use, thus the body's vibrations, due to the cardiac and respiratory cycles, may be assessed unobtrusively. Moreover, it enables measurements without the presence of medical staff, hence avoiding the stress caused by medical examinations and reducing the patient's involuntary psychophysiological responses.

New ideas for improving ballistocardiographic sensors, and digital data processing are being evaluated, although indirectly, in polysomnographic applications. What's more, the results on continuous sleep monitoring point several interesting physiological parameters which ballistocardiography may be used to gather, such as leg movements, body position, sleep classification, et cetera. However, ballistocardiography is not limited to overnight monitoring, as it is a wide-ranging option for homecare systems. Embedding sensors in the environment, in such objects as chairs and wheelchairs, bathroom scales, carpets, and pillows, will allow ubiquitous monitoring of daily-life activities, helping the e-health system to personalize the interpretation of the user's condition.

Further inspection of the physiological events related to the ballistocardiographic waves is also important, since the available knowledge was obtained using obsolete instrumentation, and is not rock-solid. Many important results are available with several studies allowing the definition of the main characteristics of the ballistocardiogram. However, updating the old experiments, and correlating the results with physiological parameters used nowadays, would be useful and helpful in making clear the doubts aroused from the previous studies.

From the current state-of-the-art, it is already possible to unobtrusively monitor respiratory rate, pulse arrival time, and the variabilities of heart rate and blood pressure [58, 61], and progressing steps are being made to extend these capabilities into more uncontrolled scenarios $[62,126]$, but there is much space for improvements, namely to guarantee good quality acquisition in most home settings.

Ballistocardiography emerged as a signal which allows profound knowledge on the cardiovascular system status. Therefore an interesting goal in the future would be to integrate physiological models' relations with the ballistocardiogram, and fuse other sensors' data with it, in order to generate new and more complete biomedical knowledge.

The impact of automatically measuring the important features of the ballistocardiogram is immense. However, in uninhibited environments, such as the homecare scenario, a harsh signal-to-noise ratio is encountered in ballistocardiogram acquisition. Renewing efforts in developing robust ballistocardiographic systems is a task promising high-payoff. Nevertheless, due to the difficulties encountered to do so, alternative approaches to this objective are to be considered, namely obtaining the ballistocardiogram indirectly. Modelling the physiological relations to other physiological signatures, and integrating 
data from other biological signals is a possible answer to this challenge, maximizing its effectiveness if incorporated in the Virtual Physiological Human framework.

Bringing the ballistocardiogram to home e-health systems is both desirable and useful, as it has unquestionable capabilities in describing and predicting the cardiovascular condition of humans. The profoundness of the information provided by the ballistocardiogram is a worthy recompense to the systems which can tackle the current limitations in the automatic mining of information from ballistocardiographic data.

\section{ACKNOWLEDGEMENTS}

The support of Instituto de Telecomunicações and Fundação para a Ciência e Tecnologia (grant SFRH/BD/ 46772/2008 and project RIPD/APD/109639/2009) are kindly appreciated. The authors are also thankful to the important help of Gabriela Postolache, Universidade Atlântica, Portugal, and to Elisabete Lopes, Instituto Politécnico de Setúbal, Portugal.

\section{REFERENCES}

[1] NASA, "Ballistocardiography - a bibliography," NASA SP-7021 (FAA AM 65-15), September 1965.

[2] W. R. Scarborough and B. M. Baker, "Ballistocardiography appraisal of current status," Circulation, vol. 16, pp. 971-975, 1957.

[3] R. S. Gubner, M. Rodstein, and H. E. Ungerleider, "Ballistocardiography - an appraisal of technic, physiologic principles, and clinical value," Circulation, vol. 7, pp. 268-286, 1953.

[4] J. W. Gordon, "On certain molar movements of the human body produced by the circulation of the blood," J. Anat. Physiol., vol. 11, pp. $533,1877$.

[5] Y. Henderson, "The mass-movements of the circulation as shown by a recoil curve," Am. J. Physiol., vol. 14, pp. 287, 1905.

[6] I. Starr, A. J. Rawson, and H.A. Schroeder, "Apparatus for recording the heart's recoil and the blood's impacts in man (ballistocardiograph), experiments on the principles involved, records in normal and abnormal conditions," in Proceedings of the Am. Physiol. SOC. 50 th Annual Meeting. Am. J. Physiol., vol. 123, pp. 195, 1938.

[7] I. Starr, A.J. Rawson, H.A. Schroeder, and N.R. Joseph, "The estimation of cardiac output and the determination of the blood's impacts (ballistocardiogram)," in Proceedings Am. Soc. Clin. Invest. 30th Annual Meeting, J. Clin. Invest., vol. 17, pp. 506, 1938.

[8] I. Starr, A.J. Rawson, H.A. Schroeder, and N. R. Joseph, "Studies on the estimation of cardiac output in man, and of abnormalities in cardiac function from the heart's recoil and the blood's impact; the ballistocardiogram," Am. J. Physiol., vol. 127, pp. 1, 1939.

[9] J. L. Nickerson and H. J. Curtis, "The design of the ballistocardiograph," Am. J. Physiol., vol. 142, pp. 1, 1944.

[10] W. W. von Wittern, "Ballistocardiography with elimination of the influence of the vibration properties of the body," Am. Heart J., vol. 46 , pp. 705,1953 .

[11] S.A. Talbot, D.C. Deuchar, F.W. Davis Jr., and W.R. Scarborough, "The aperiodic ballistocardiograph," Bull. Johns Hopkins Hosp., vol. 94, pp. 27, 1954.

[12] H.C. Burger, A. Noordergraaf, and M.W. Verhagen, "Physical basis of the low-frequency ballistocardiograph," Am. Heart J., vol. 46, pp. 71, 1953.

[13] M.B. Rappaport, "Considerations in ballistocardiography," Mod. Concepts Cardiovasc. Dis., vol. 24, no. 6, pp. 277-281, June 1955.

[14] M.B. Rappaport, "Displacement, velocity and acceleration ballistocardiograms as registered with an undamped bed of ultralow natural frequency," Am Heart J., vol. 52, no. 5, pp. 643-652, November 1956.
[15] J. E. Smith and T. Perls, "A calibrated barmagnet velocity meter for use in ballistocardiography," Am. Heart J., vol. 44, pp. 872, 1952.

[16] S. R. Arbeit and N. Linder, "A new full-frequency range calibrated ballistocardiograph. i. recording the body ballistics in displacement, velocity and acceleration," Am. Heart J., vol. 45, pp. 52, 1953.

[17] R. P. Walker, T. J. Reeves, K. Willis, L. Christianson, R. J. Pierce, and D. Kahn, "The effect of surface and recording technique on the direct ballistocardiogram," Am. Heart J., vol. 46, pp. 2, 1953.

[18] W. Dock and F. Taubman, "Some technics for recording the ballistocardiogram directly from the body," Am. J. Med., vol. 7, pp. $751,1949$.

[19] W. Dock, F. Taubman, H. Mandelbaum, and R.A. Mandelbaum, Ballistocardiography, St. Louis: C. V. Mosby. Co., 1953.

[20] V. Masini and P. Rossi, "A new index for quantitative ballistocardiography - the velocity of body displacement," Circulation, vol. 8, pp. 276-281, 1953.

[21] J. L. Brandt, A. Caccese, W. Dock, and A. Schrager, "The motion of the thorax during the heart cycle. A comparison of longitudinal, lateral, and dorsoventral ballistocardiograms," J. Clin. Invest., vol. 30, pp. 971, 1951.

[22] R. J. Jones, "The Nickerson ballistocardiograph in arteriosclerotic heart disease with and without congestive failure," Circulation, vol. 6, pp. 389, 1952.

[23] N. S. Blackman, "Identification of the cofriplexes of the electromagnetic ballistocardiograph in a single channel," Am. Heart J., vol. 43, pp. 840, 1952.

[24] J. L. Nickerson, "Some observations on the ballistocardiographic pattern with special reference to the $\mathrm{h}$ and $\mathrm{k}$ waves," J. Clin. Invest., vol. 28, pp. 369, 1949.

[25] W. F. Hamilton, J. Remington, and P. Dow, "Relationship between cardiac ejection curve and ballistocardiographic forces," Am. J. Physiol., vol. 144, pp. 557, 1945.

[26] R. Gubner, M. Rodstein, and H.E. Ungerleider, "The ballistocardiogram: normal standards and determinants of the waves," in Proceedings of the $23^{\text {rd }}$ Sc. Sessions Am. Heart A., June 1950, pp. 22-24.

[27] I. Starr and C. Friedland, "On cause of respiratory variation of ballistocardiogram with note on sinus arrythmia," J. Clin. Invest., vol. 25, pp. 53, 1946.

[28] W. F. Hamilton and P. Dow, "Cardiac and aortic contributions to the human ballistocardiogram," Am. J. Physiol., vol. 133, pp. 313, 1941.

[29] H. R. Brown Jr., M. J. Hoffman, and V. Delalla Jr., "Ballistocardiograms in coarctation of the aorta," New England $J$. Med., vol. 240, pp. 715, 1949.

[30] J. L. Nickerson, G. H. Humphreys, R. A. Deterling, T. C. Fleming, and J. A. L. Mathers, "Diagnosis of coarctation of the aorta with the aid of the low-frequency, critically-damped ballistocardiograph," Circulation, vol. 1, pp. 1032, 1950.

[31] R. A. Murphy, "Ballistocardiographic patterns in intraluminal aortic obstructions," Am. Heart J., vol. 39, pp. 174, 1950.

[32] H. R. Brown Jr., M. J. Hoffman, and V. Delalla Jr., "Ballistocardiographic findings in patients with angina pectoris," Circulation, vol. 1, pp. 132, 1950.

[33] J. A. L. Mathers, J. L. Nickerson, T. C. Fleming, and M. C. Patterson, "Abnormal ballistocardiographic patterns in cardiovascular disease as recorded with the low-frequency, critically-damped ballistocardiograph," Am. Heart J., vol. 40, pp. 390, 1950.

[34] M. Moser, L. Pordy, K. Chesky, R.C. Taymor, and A.M. Master, "The ballistocardiogram in myocardial infarction. a study of 100 cases," Circulation, vol. 6, pp. 402, 1952.

[35] L. Pordy, R. C. Taymor, M. Moser, K. Chesky, and A. M. Master, "Clinical evaluation of the ballistocardiogram. ii. heart disease, hypertension, angina pectoris, and myocardial infarction," Am. Heart J., vol. 42, pp. 321-328, 1951.

[36] B. M. Baker Jr., W. R. Scarborough, M. L. Singewald, R. E. Mason, and F. W. Davis Jr. "Ballistocardiography in patients with coronary artery disease and in apparently normal persons," in Proceedings of the Am. A. Adv. Sc., December 1951. 
[37] B. Berman, J. R. Braunstein, and J. Mcguire, "The effect of meals on the electrocardiogram and the ballistocardiogram in patients with angina pectoris," Circulation, vol. 1, pp. 1017, 1950.

[38] R. Gubner, "The diagnosis of arteriosclerosis, including observations on lipid metabolism and the ballistocardiogram," Trans. Assoc. Life Insur. Med. Dir. Am., vol. 34, pp. 20, 1950.

[39] D.H. Makinson, "Changes in the ballistocardiogram after exercise in normal and abnormal subjects," Circulation, vol. 2, pp. 186, 1950 .

[40] A. Noordergraaf, "Physical aspects of the direct recording of body displacement, velocity, and acceleration by shin-bar ballistocardiographs," Circulation, vol. 23, pp. 426-433, 1961.

[41] S. A. Talbot and W. K. Harrison Jr, "Dynamic comparison of current ballistocardiographic methods part i. artefacts in the dynamically simple ballistocardiographic methods," Circulation, vol. 12 , pp. $577-587,1955$.

[42] S. A. Talbot and W. K. Harrison Jr, "Dynamic comparison of current ballistocardiographic methods part ii. effect of a platform in ballistocardiographic dynamics," Circulation, vol. 12, pp. 845-857, 1955.

[43] S. A. Talbot and W. K. Harrison Jr, "Dynamic comparison of current ballistocardiographic methods part iii. derivation of cardiovascular force from body motions," Circulation, vol. 12, pp. 1022-1033, 1955

[44] M. B. Rappaport, H. B. Sprague, and W. B. Thompson, "Ballistocardiography i. physical considerations," Circulation, vol. 7, pp. 229-246, 1953.

[45] R. V. Elliott, R. G. Packard, and D. T. Kyrazis "Acceleration ballistocardiography: design, construction, and application of a new instrument," Circulation, vol. 9, pp. 281-291, 1954.

[46] John R. Braunstein, "A proposed nomenclature and convention for recording the ballistocardiogram," Circulation, vol. 7, pp. 927-928, 1953.

[47] I. Starr, J. R. Braunstein, W. Dock, R. Gubner, W. F. Hamilton, J. L. Nickerson, M. B. Rappaport, W. R. Scarborough, and J. E. Smith, "First report of the committee on ballistocardiographic terminology," Circulation, vol. 7, pp. 929-931, 1953.

[48] R. S. William, A. T. Samuel, R. B. John, B. R. Maurice, D. William, R. S. William, W. F. Hamilton, E. S. John, L. N. John, A. T. Samuel, S. Isaac, "Proposals for ballistocardiographic nomenclature and conventions - revised and extended report of committee on ballistocardiographic terminology," Circulation, vol. 14, pp. 435-450, 1956.

[49] I. Starr, "Normal standards for amplitude of ballistocardiograms calibrated by force," Circulation, vol. 11, pp. 914-926, 1955.

[50] L. Kobza and A. Scheurich, "The impact of telemedicine on outcomes of chronic wounds in the home care setting," Ostomy Wound Manage, vol. 46, pp. 48-53, 2000.

[51] B. Leff and J.R. Burton, "The future of home care and physician house calls in the united states," J. Gerontol. A. Biol. Sci. Med. Sci., vol. 56, pp. 603-608, 2001.

[52] S. Myers, R.W. Grant, N.E. Lugn, B. Holbert, and J. Kvedar, "Impact of home based monitoring on the care of patients with congestive heart failure," Home Health Care Manag. Pract., vol. 18, no. 6, pp. 441-451, 2006.

[53] G. Berntson, J. Cacciopo, K. Quigley, and V. Fabro, "Autonomic space and psychophysiological response," Psychophysiology, vol. 31, no. 1, pp. 44-61, 1994.

[54] M. Erkinjuntti, K. Vaahtoranta, J. Alihanka, and P. Kero, "Use of the scsb method for monitoring of respiration, body movents and ballistocardiogram in infants," Early Human Dev., vol. 9, pp. 119126, 1984.

[55] A. Lee, "Method for preparing a ballistocardiogram," U.S. Patent 4,836,215, June 6, 1989

[56] J. Lekkala and M. Paajanen, "EMFi - new electret material for sensors and actuators," in Proceedings of the $10^{\text {th }}$ IEEE International Symposium On Electrets, Delphi, Greece, pp. 743746, September 1999.

[57] K. Kirjavainen, "Electromechanical film and procedure for manufacturing same," U.S. Patent 4,654,546, March 31, 1987.

[58] O. Postolache, G. Postolache, and P. Girão, "New device for assessment of autonomous nervous system functioning in psychophysiology," in Proceedings of the 2007 IEEE Int. Workshop on Med. Meas. and Applications, Warsaw, Poland, pp. 1-5, May 2007

[59] T. Koivistoinen, S. Junnila, A. Värri, and T. Koobi, "A new method for measuring the ballistocardiogram using emfi sensors in a normal chair," in Proceedings of the $26^{\text {th }}$ IEEE EMBS Annual International Conference, San Francisco, USA, pp. 2026-2029, September 2004

[60] S. Junnila, A. Akhbardeh, L.C. Barna, I. Defee, and A. Värri, "A wireless ballistocardiographic chair," in Proceedings of the $28^{\text {th }}$ IEEE EMBS Annual International Conference, New York, USA, pp. 5932-5935, September 2006.

[61] E.C. Pinheiro, O. Postolache, and P. Girão, "Pulse arrival time and ballistocardiogram application to blood pressure variability estimation," in Proceedings of the $4^{\text {th }}$ IEEE Int. Work. on Medical Measurements and Applications, Cetraro, Italy, pp. 132-136, May 2009.

[62] J.M. Kim, J.H. Hong, M.C. Cho, E.J. Cha, and T.S. Lee, "Wireless biomedical signal monitoring device on wheelchair using noncontact electro-mechanical film sensor," in Proceedings of the $29^{\text {th }}$ IEEE EMBS Annual International Conference, Lyon, France, September 2007, pp. 574-577.

[63] A. Akhbardeh, S. Junnila, T. Koivistoinen, T. Koobi, and A. Varri, "Ballistocardiogram Classification Using A Novel Transform SoCalled Alimap and Biorthogonal Wavelets," in Proceedings of the 2005 IEEE Int. Work. on Intelligent Signal Processing, Faro, Portugal, pp. 64-69, 2005.

[64] S. Junilla, A. Akhbardeh, A. Varri, and T. Koivistoinen, "An emfifilm sensor based ballistocardiographic chair performance and cycle extraction method," in Proceedings of the 2005 IEEE Work. on Signal Processing Systems Design and Implementation, Athens, Greece, pp. 373-377, 2005.

[65] A. Akhbardeh, S. Junnila, T. Koivistoinen, and A. Varri, “Applying novel supervised fuzzy adaptive resonance theory (sf-art) neural network and biorthogonal wavelets for ballistocardiogram diagnosis," in Proceedings of the 2006 IEEE Int. Symp. on Intelligent Control, Munich, pp. 143-148, 2006.

[66] I. Akhbardeh, S. Junilla, and A. Varri, "Applying biorthogonal wavelets and a novel quicklearn algorithm for an intelligent ballistocardographic chair," in Proceedings of the 2006 Mountain Work. on Adaptative and Learning Systems, Logan, USA pp. 4247, 2006.

[67] I. Akhbardeh, M. Koivuluoma, T. Koivistoinen, and A. Varri, "BCG data clustering using new method so-called time-frequency moments singular value decomposition (tfm-svd) and artificial neural networks," in Proceedings of the 2005 IEEE Int. Symp. on Intelligent Control, Limassol, Cyprus, pp. 1447-1451, 2005.

[68] A. Akhbardeh, S. Junilla, T. Koivistoinen, and A. Varri, "Design an intelligent ballistocardiographic chair using novel quicklearn and sf-art algorithms and biorthogonal wavelets," in Proceedings of the 2006 IEEE Int. Conf. on Systems Man and Cybernetics, Taipei, pp. 878-883, 2006.

[69] A. Akhbardeh, S. Junilla, M. Koivuluoma, T. Koivistoinen, and A. Varri, "The heart disease diagnosing system based on force sensitive chair's measurement, biorthogonal wavelets and neural networks," in Proceedings of the 2005 IEEE/ASME Int. Conf. On Advanced Intelligent Mechatronics, Monterey, Uruguay, pp. 676681, 2005.

[70] A. Akhbardeh, S. Junilla, M. Koivuluoma, T. Koivistoinen, and A. Varri, "Evaluation of heart condition based on ballistocardiogram classification using compactly supported wavelet transforms and neural networks," in Proceedings of the 2005 IEEE Int. Conf. on Control Applications, Toronto, Canada, pp. 843-848, 2005.

[71] A. Selzer, "Fifty years of progress in cardiology: a personal perspective," Circulation, vol. 77, pp. 955-963, 1988.

[72] Word Health Organization, "Chronic diseases and health promotion" Available: http://www.who.int/chp/en/index.html [Accessed December 12, 2008].

[73] V. L. Delalla Jr., M. A. Epstein, and H. R. Brown, "Analysis of the h wave of the ballistocardiogram," Circulation, vol. 2, pp. 765 , 1950.

[74] P. Pollock, "Ballistocardiography a clinical review," Canad. Med. Assoc. J., vol. 76, pp. 778-783, May 1957. 
[75] T. J. Reeves, L. L. Hefner, W. B. Jones, and J. E. Sparks, "Wide frequency range force ballistocardiogram - its correlation with cardiovascular dynamics," Circulation, vol. 16, pp. 43-53, 1957.

[76] H. D. Lauson, R. A. Bloomfield, and A. Cournand, "Influence of respiration on circulation in man with special reference to pressures in the right auricle, right ventricle, femoral artery and peripheral veins," Am. J. Med., vol. 1, pp. 315, 1946.

[77] A. Cournand, "Recent observations on dynamics of pulmonary circulation," Bull. New York Acad. Med., vol. 23, pp. 27, 1947.

[78] F. W. Davis Jr., W. R. Scarborough, R. E. Mason, and M. L. Singewald, "The effects of exercise and smoking on the electrocardiograms and ballistocardiograms of normal subjects and patients with coronary artery disease," Am. Heart J., vol. 46, pp. 529, October 1953.

[79] A. L. Messer, T. B. Counihan, M. B. Rappaport, and H. B. Sprague, "The effect of cycle length on the time of the occurrence of the first heart sound and opening snap in mitral stenosis," Circulation, vol. 4, pp. 576, 1951.

[80] T. Lewis, "The time relationship of the heart sounds and murmurs with special reference to the acoustic signs in mitral stenosis," Heart, vol. 4, pp. 241, 1912.

[81] P. J. T. A. Battaerd, "Further graphic research on the acoustic phenomena of the heart in normal and pathological conditions," Heart, vol. 6, pp. 121, 1915-17.

[82] C. J. Wiggers, Circulation In Health and Disease. Philadelphia: Lea \& Febiger, 1923.

[83] C. J. Wiggers, Physiology In Health and Disease. Philadelphia: Lea \& Febiger, 1939.

[84] A. C. Taquini, B. F. Massell, and B. J. Walsh, "Phonocardiographic studies of early rheumatic mitral disease," Am. Heart J., vol. 20, pp. 295, 1940.

[85] A. Luisada, "Variable interval between electrical and acoustic phenomena in auricular fibrillation," Am. Heart J., vol. 22, pp. 245, 1941.

[86] M. B. Rappaport, and H. B. Sprague, "Physiologic and physical laws that govern auscultation and their clinical appreciation," $\mathrm{Am}$. Heart J., vol. 21, pp. 257, 1941.

[87] D. P. Osborn and A. F. Fath, "The graphic registration of the normal heart action," J. Med., vol. 22, pp. 5, 1941.

[88] C.J. Wiggers, Physiology In Health and Disease. Philadelphia: Lea \& Febiger, 1949.

[89] A. A. Luisada and S. Contro, "On the time relationship of the waves of the ballistocardiogram," Acta Cardiologica, vol. 5, pp. 847,1951

[90] O. Tannenbaum, J. A. Schack and H: Vesell, "Relationship between ballistocardiographic forces and certain events in the cardiac cycle," Circulation, vol. 6, pp. 586-592, 1952.

[91] W. B. Thompson, M. B. Rappaport, and H. B. Sprague, "Ballistocardiography ii. the normal ballistocardiogram," Circulation, vol. 7, pp. 321-328, 1953.

[92] R. J. Jones and N. E. Goulder, "An empiric approach to the interpretation of the low frequency critically damped ballistocardiogram," Circulation, vol. 2, pp. 756, 1950.

[93] M. B. Rappaport and H. B. Sprague, "The graphic registration of the normal heart sounds," Am. Heart J., vol. 23, pp. 591, 1942.

[94] O. Orias and E. Braun-Menendez, The Heart Sounds In Normal and Pathological Conditions. London, Oxford Univ. Press, 1939.

[95] J. L. Nickerson, J. W. Warren, and E. S. Brannon, "The cardiac output in man; studies with the low frequency, critically-damped ballistocardiograph, and the method of right atrial catheterization," J. Clin. Invest., vol. 26, pp. 1, 1947.

[96] A. Cournand, H. A. Ranges, and R. L. Riley, "Comparison of results of the normal ballistocardiogram and a direct fick method in measuring cardiac output in man," J. Clin. Invest., vol. 21, pp. 287, 1942.

[97] J. M. Tanner, "The construction of normal standards for cardiac output in man," J. Clin. Invest., vol. 28, pp. 567, 1949.

[98] J. W. Warren, E. A. Stead Jr., and E. S. Brannon, "The cardiac output in man: a study of some of the errors in the method of right heart catheterization," Am. J. Physiol., vol. 145, pp. 458, 1946.

[99] I. Starr, O. Horwitz, R. L. Mayock, and E. B. Krumbhaar, "Standardization of the ballistocardiogram by simulation of the heart's function at necropsy; with a clinical method for the estimation of cardiac strength and normal standards for it," Circulation, vol. 1, pp. 1073, 1950.
[100] T. J. Reeves, W. B. Jones, and L. L. Hefner, "Design of an ultra low frequency force ballistocardiograph on the principle of the horizontal pendulum," Circulation, vol. 6, pp. 36-42, 1957.

[101] A. M. Master, K. Chesky, and L. Pordy, "The cardiovascular examination of 200 practicing physicians over the age of forty," New York. J. Med., vol. 51, pp. 1713, 1951.

[102] S.C. Franco, "Clinical ballistocardiography. Value and limitations of the portable ballistocardiograph in the detection of cardiac disease," Indust. Med., vol. 21, pp. 197, 1952.

[103] I. Starr, F. C Wood, and R. L. Mayock, "On the significance of abnormal forms of the ballistocardiogram: a study of 234 cases with 40 necropsies," Am. J. Med. Sci., vol. 215, pp. 631, 1948.

[104] W. Dock, H. Mandelbaum, and R. A. Mandelbaum, "Ballistocardiography in medical practice," J. Am. Med. Assoc., vol. 146, pp. 1284, 1951.

[105] M. Baker, W. R. Scarborough, F. W. Davis Jr., R. E. Mason, and M. L. Singewald (statistical evaluation: S. H. Walker, E. A. Murphy, W. K. Harrison Jr., and R. W. Sherwin), "Ballistocardiography and ischemic heart disease: predictive considerations," in Proceedings of the Roy. Soc. Med., December, 1967.

[106] I. Starr and F.C. Wood, "Twenty-year studies with the ballistocardiograph: the relation between the amplitude of the first record of "healthy" adults and eventual mortality and morbidity from heart disease," Circulation, vol. 23, pp. 714-732, 1961.

[107] R. S. Alexander, "Factors determining contour of pressure pulses recorded from the aorta," Fed. Proc., vol. 11, pp. 738, 1952.

[108] A. Cournand, R. L. Riley, S. E. Bradley, E. S. Breed, R. P. Noble, H. D. Lauson, M. I. Gregersen, and D. W. Richards, "Studies of the circulation in clinical shock," Surgery, vol. 13, pp. 964, 1943.

[109] J. W. Remington, "Volume determination of aortic pulse," Fed. Proc., vol. 11, pp. 750, 1952.

[110] W. R. Scarborough, R. E. Mason, F. W. Davis Jr., M. L. Singewald, B. M. Baker Jr., and S. A. Lore, "A ballistocardiographic and electrocardiographic study of 328 patients with coronary artery disease: comparison with results from a similar study of apparently normal persons," Am. Heart J., vol. 44, pp. 645, 1952.

[111] I. Starr, "The ballistocardiograph. an instrument for clinical research and for routine clinical research and for routine clinical diagnosis," Harvey Lect., vol. 42, pp. 194, 1946-47.

[112] I. Starr, "Clinical studies with the ballistocardiograph; in congestive failure, on digitalis action, on changes in ballistic form, and in certain acute experiments," Am. J. Med. Sci., vol. 202, pp. $469,1941$.

[113] L. J. Acierno and R. Gubner, "Utility and limitations of intravenous quinidine in arrhythmias," Am. Heart J., vol. 41, pp. 733, 1951.

[114] L. A. Nalefski, W. B. Rudy, and N. C. Gilbert, "The use of crystalline visammin in the treatment of angina pectoris," Circulation, vol. 5, pp. 851, 1952.

[115] J. L. Brandt, A. Caccese, and W. Dock, "Slit-kymographic evidence that nitroglycerin decreases heart volume and stroke volume, while increasing the amplitude of ballistocardiographic waves," Am. J. Med., vol. 12, pp. 650, 1952.

[116] A. Caccese, and A. Schrager: "The effects of cigarette smoking on the ballistocardiogram," Am. Heart J., vol. 42, pp. 589, 1951.

[117] H. Mandelbaum, R. A. Mandelbaum, "Studies utilizing the portable electromagnetic ballistocardiograph. ii. the ballistocardiogram as a means of determining nicotine sensitivity," Circulation, vol. 5, pp. $885,1952$.

[118] R. L. Mayock, C. E. Riegel, C. Koop, N. T. Kough, and I. Starr, "Convalescence from surgical procedures. iii. the relation of nitrogen balance and blood volume to abnormalities of the circulation," Am. J. Med. Sc., vol. 212, pp. 591, 1946.

[119] E. Donoso, L. Pordy, Y.Z. Yuceoglu, J.B. Minor, K. Chesky, and S.S. Amram, "The ballistocardiogram in congenital heart disease," Am. Heart J., vol. 52, no. 3, pp. 352, 1956.

[120] I. Starr, "Essay on the ballistocardiogram," J. Am. Med. Assoc., vol. 155, pp.1413, 1954.

[121] J. L. Brandt, A. Caccese, W. Dock, and A. Schrager, "The motion of the thorax during the heart cycle. a comparison of longitudinal, lateral, and dorsoventral ballistocardiograms," J. Clin. Investig., vol. 30, pp. 971, 1951. 
[122] J. R. Braunsstein, C. E. Oelker and R. C. Gowdy, "Design of a twodimensional ballistocardiograph,” J. Clin. Invest., vol. 29, pp. 1219, 1950.

[123] S. A. Franzblau, W. R. Best, V. Guillemin Jr., and J. P. Marbarger, "Three dimensional vector ballistocardiography," in Proceedings of the Central Soc. Clin. Res., Nov. 1950, J. Lab. Clin. Med., vol. 36, pp. 824, 1950.

[124] W. R. Scarborough, J. Beser, S. A. Talbot, R. E. Mason, M. L. Singewald, and B. M. Baker Jr., "A method for recording ballistocardiographic vectors," Preliminary Report. Bull. Johns Hopkins Hosp., vol. 87, pp. 235, 1950.

[125] A. Sheehan Jr., F. K. Priebe, A. I. Dranetz, and G. N. Howatt, "Practical clinical application of new piezoelectric material ballistocardiograph,” Bull. New York Acad. Med., vol. 26, pp. 263, 1950.

[126] O. Postolache, P. Girão, J. Joaquim, G. Postolache, "Unobstrusive heart rate and respiration rate monitor embedded on a wheelchair," in Proceedings of the $4^{\text {th }}$ IEEE Int. Work. on Medical Measurements and Applications, Cetraro, Italy, May pp. 83-88, 2009.

[127] O. Postolache, P. Girão, G. Postolache, and M. Pereira, "Vital signs monitoring system based on emfi sensors and wavelet analysis," in Proceedings of the 2007 IEEE Instrumentation and Measurement Technology Conference, Warsaw, Poland, pp. 1-4, May 2007.

[128] X. Yu, D. Gong, X. Shuen, S. Li, and Y. Xu, "Comparisons of a combined wavelet and a combined principal component analysis classification model for BCG signal analysis," in Proceedings of the 2003 IEEE Int. Conf. on Rob. Intelligent Syst. and Signal Processing, Chagsha, China, pp. 160-165, October 2003.

[129] W. Nakamura, K. Anami, T. Mori, O. Saitoh, A. Cichocki, and S. Amari, "Removal of bcg artifacts from simultaneously recorded eeg and fmri data using independent component analysis," IEEE Trans. Biomed. Eng., vol. 53, no. 7, pp. 1294-1308, July 2006.

[130] M. Koskinen and N. Vartiainen, "Removal of ballistocardiogram artifact from eeg data acquired in the mri scanner: selection of ica components," in Proceedings of the $30^{\text {th }}$ IEEE EMBS Annual International Conference, Vancouver, Canada, pp. 5220-5223, August 2008.

[131] A. Mahadevan, D. H. Mugler, and S. Acharya, "Adaptive filtering of ballistocardiogram artifact from eeg signals using the dilated discrete Hermite transform," in Proceedings of the $30^{\text {th }}$ IEEE EMBS Annual International Conference, Vancouver, Canada, pp. 2630-2633, August 2008

[132] F. Grouiller, L. Vercueil, A. Krainik, C. Segebarth, P. Kahane, and O. David, "A comparative study of different artefact removal algorithms for eeg signals acquired during functional mri," NeuroImage, vol. 38, pp. 124-137, 2007.

[133] E. Pinheiro, O. Postolache, and P. Girão, "Blood Pressure and Heart Rate Variabilities Estimation Using Ballistocardiography," in Proceedings of the $7^{\text {th }}$ Conf. on. Telecom., Santa Maria da Feira, Portugal, pp. 125-128, May 2009.

[134] Task force of the European society of cardiology and the North American society of pacing and electrophysiology, "Heart rate variability - standards of measurement, physiological interpretation, and clinical use," Circulation, vol. 93, iss. 5, pp. 1043-1065, 1996.

[135] G.G. Berntson, J.T. Cacciopo, K.S. Quigley, and V.T. Fabro, "Autonomic space and psychophysiological response," Psychophysiology, vol. 31, no. 1, pp. 44-61, 1994.

[136] G. Parati, J. P. Saul, M. D. Rienzo, and G. Mancia, "Spectral analysis of blood pressure and heart rate variability in evaluating cardiovascular regulation: a critical appraisal," Hypertension, vol. 25, pp. 1267-1286, 1995.

[137] S. L. Dawson, B. N. Manktelow, T. G. Robinson, R. B. Panerai, and J. F. Potter, "Which parameters of beat-to-beat blood pressure and variability best predict early outcome after acute ischemic stroke?," Stroke, vol. 31, pp. 463-468, 2000.

[138] O. Postolache, P.S. Girão, and G. Postolache, "New approach on cardiac autonomic control estimation based on bcg processing," in Proceedings of the 2007 Canadian Conf. Electrical Eng., Vancouver, Canada, pp. 876-879, April 2007.

[139] Y. Kiu, C. Poon, and Y. Zhang, "A hydrostatic calibration method for the design of wearable pat-based blood pressure monitoring devices," in Proceedings of the $30^{\text {th }}$ IEEE EMBS Annual International Conference, Vancouver, Canada, pp. 1308-1310, August 2008.

[140] T. Ma and Y. T. Zhang, "A correlation study on the variabilities in pulse transit time, blood pressure, and heart rate recorded simultaneously from healthy subjects," in Proceedings of the $27^{\text {th }}$ IEEE EMBS Annual International Conference, Shanghai, China, pp. 996-999, September 2005.

[141] L. A. Geddes, M. Voelz, S. James, and D. Reiner, "Pulse arrival time as a method of obtaining systolic and diastolic blood pressure indirectly," Med. Biol. Eng. Comput., vol. 19, pp. 671-672, 1981.

[142] I. Pinhas, A. Halperin, A. Averboukh, D. Lange, Y. Gross, "Methods and systems to monitor patients for clinical episodes," US Patent 2007/0118054 A1, May 24, 2007.

[143] D.C. Mack, S. Kell, M. Alwan, R. Felder, B. Turner, and S. Wood, "System and process for non-invasive collection and analysis of physiological signals," US Patent 7,396,331, July 8, 2008.

[144] K. Schlager, B. Boehlen, and S. Gorski, "Automatic seismic detection of myocardial ischemia and related measurement of cardiac output parameters," US Patent 6,024,705, February 15, 2000 .

[145] N. Berne, H. Guler, "Method for analysis of abnormal body tremors," US Patent 6,936,016 B2, August 30, 2005.

[146] J. Manolas, "Device for and method of rapid noninvasive measurement of parameters of diastolic function of left ventricle and automated evaluation of the measured profile of left ventricular function at rest and with exercise," US Patent 2003/0204145 A1, October 30, 2003.

[147] D.C. Mack, J.T. Patrie, P.M. Suratt, R.A. Felder, and M. Alwan, "Development and preliminary validation of heart rate and breathing rate detection using a passive, ballistocardiography-based sleep monitoring system," IEEE Trans. Inform. Technol. Biomed., vol. 13, no. 1, pp. 111-120, January 2009.

[148] C. Mack, S. Kell, M. Alwan, B. Turner, and R. A. Felder, "Noninvasive analysis of physiological signals (naps): a vibration sensor that passively detects heart and respiration as a part of a sensor suite for medical monitoring," in Proceedings of the Summer Bioeng. Conf., Key Biscayne, USA, June 2003.

[149] C. Mack, M. Alwan, B. Turner, P. Suratt, and R. A. Felder, "A passive and portable system for monitoring heart rate and detecting sleep apnea and arousals: Preliminary validation," in Proceedings of the Distrib. Diagnosis Home Healthcare Conf., Arlington, USA, pp. 51-54, 2006.

[150] P. Chow, G. Nagendra, J. Abisheganaden, and Y. T. Wang, "Respiratory monitoring using an air-mattress system," Physiol. Meas., vol. 21, pp. 345-354, 2000.

[151] H. van Der Loos, H. Kobayashi, G. Liu, Y.Y. Tai, J. Ford, J. Norman, T. Tabata, and T. Osada, "Unobtrusive vital signs monitoring from a multisensor bed sheet," in Proceedings of the RESNA Conf., Reno, USA, pp. 218-220, June 2001.

[152] F. Wang, M. Tanaka, and S. Chonan, "Development of a pvdf piezopolymer sensor for unconstrained in-sleep cardiorespiratory monitoring," J. Intell. Mater. Syst. Struct., vol. 14, pp. 185-190, 2003.

[153] T. Watanabe and K. Watanabe, "Noncontact method for sleep stage estimation," IEEE Trans. Biomed. Eng., vol. 51, no. 10, pp. 1735 1748, October 2004.

[154] Y. Chee, J. Han, J. Youn, and K. Park, "Air mattress sensor system with balancing tube for unconstrained measurement of respiration and heart beat movements," Physiol. Meas., vol. 26, pp. 413-422, 2005.

[155] W. Chen, X. Zhu, T. Nemoto, Y. Kanemitsu, K. Kitamura, and K. Yamakoshi, "Unconstrained detection of respiration rhythm and pulse rate with one under-pillow sensor during sleep," Med. Biol. Eng. Comput., vol. 43, pp. 306-312, 2005.

[156] M. Brink, C. H. Muller, and C. Schierz, "Contact-free measurement of heart rate, respiration rate, and body movements during sleep," Behav. Res. Methods, vol. 38, pp. 511-521, 2006.

[157] Y. Kamozaki, T. Sawayama, K. Taniguchi, S. Kobashi, K. Kondo, and Y. Hata, "A new ultrasonic oscillosensor and its application in biological information measurement system aided by fuzzy 
theory," IEICE Trans. on Information and Systems, vol. E90-D, no. 11, pp. 1864-1872, November 2007.

[158] W. C. Orr and S. Goodrich, "An investigation of the accuracy of the lifeshirt in comparison to standard polysomnography," Sleep Med., vol. 10, no. 1, pp. 118-122, January 2009.

[159] D. Claman, A. Murr, and K. Trotter, "Clinical validation of the bedbugg in detection of obstructive sleep apnea," Otolaryngol. Head Neck Surg., vol. 125, pp. 227-230, 2001.

[160] N. T. Ayas, S. Pittman, M. MacDonald, and D. P. White, "Assessment of a wrist-worn device in the detection of obstructive sleep apnea," Sleep Med., vol. 4, pp. 435-442, 2003.
[161] L. Guohua, W. Jianqi, Y. Yu, and J. Xijing, "Study of the ballistocardiogram signal in non-contact life detection system based on radar," in Proceedings of the $29^{\text {th }}$ IEEE EMBS Annual International Conference, Lyon, France, pp. 2191-2194, August 2007.

[162] O. Postolache, P. Girão, R. Madeira, and G. Postolache, "Microwave FMCW Doppler radar implementation for in-house pervasive health care system," in Proceedings of the $5^{\text {th }}$ IEEE Int. Work. on Medical Measurements and Applications, Ottawa, Canada, pp. 47-52, April 2010.

Received: February 16, 2010

(C) Pinheiro et al.; Licensee Bentham Open.

This is an open access article licensed under the terms of the Creative Commons Attribution Non-Commercial License (http://creativecommons.org/licenses/by-nc/3.0/) which permits unrestricted, non-commercial use, distribution and reproduction in any medium, provided the work is properly cited. 